\title{
Stage IV Nasal Cavity and Paranasal Sinus Squamous Cell Carcinoma AJCC v7
}

National Cancer Institute

\section{Source}

National Cancer Institute. Stage IV Nasal Cavity and Paranasal Sinus Squamous Cell

Carcinoma A/CC V7. NCI Thesaurus. Code C115073.

Stage IV includes: IVA: (T4a, N0, M0); (T4a, N1, M0); (T1, N2, M0); (T2, N2, M0); (T3, N2, M0); (T4a, N2, M0); IVB: (T 4b, Any N, M0); (Any T, N3, M0); IVC: (Any T, Any N, M1). T4a: Maxillary sinus: Moderately advanced local disease. Tumor invades anterior orbital contents, skin of cheek, pterygoid plates, infratemporal fossa, cribriform plate, sphenoid or frontal sinuses. Nasal cavity and ethmoid sinus: Moderately advanced local disease. Tumor invades any of the following: anterior orbital contents, skin of nose or cheek, minimal extension to anterior cranial fossa, pterygoid plates, sphenoid or frontal sinuses. T4b: Very advanced local disease. Tumor invades any of the following: orbital apex, dura, brain, middle cranial fossa, cranial nerves other than maxillary division of trig eminal nerve, nasopharynx, or clivus. N0: No regional lymph node metastasis. N1: Metastasis in a single ipsilateral lymph node, $3 \mathrm{~cm}$ or less in greatest dimension. N2: Metastasis in a single ipsilateral lymph node, more than $3 \mathrm{~cm}$ but not more than $6 \mathrm{~cm}$ in greatest dimension, or in multiple ipsilateral lymph nodes, none more than $6 \mathrm{~cm}$ in greatest dimension, or in bilateral or contralateral lymph nodes, none more than $6 \mathrm{~cm}$ in greatest dimension. N3: Metastasis in a lymph node, more than $6 \mathrm{~cm}$ in greatest dimension. M0: No distant metastasis. M1: Distant metastasis. (AJCC 7th ed.) 